\title{
Expansion of the Hadley Cell under Global Warming: Winter versus Summer
}

\author{
SARAH M. KANG \\ School of Urban and Environmental Engineering, Ulsan National Institute of Science and Technology, Ulsan, South Korea \\ JIAN LU \\ Center for Ocean-Land-Atmosphere Studies, Institute of Global Environment and Society, Calverton, Maryland, \\ and Department of Atmospheric, Oceanic and Earth Sciences, George Mason University, Fairfax, Virginia
}

(Manuscript received 6 June 2012, in final form 13 September 2012)

\begin{abstract}
A scaling relationship is introduced to explain the seasonality in the outer boundary of the Hadley cell in both climatology and trend in the simulations of phase 3 of the Coupled Model Intercomparison Project (CMIP3). In the climatological state, the summer cell reaches higher latitudes than the winter cell since the Hadley cell in summer deviates more from the angular momentum conserving state, resulting in weaker upper-level zonal winds, which enables the Hadley cell to extend farther poleward before becoming baroclinically unstable. The Hadley cell can also reach farther poleward as the ITCZ gets farther away from the equator; hence, the Hadley cell extends farther poleward in solstices than in equinoxes. In terms of trend, a robust poleward expansion of the Hadley cell is diagnosed in all seasons with global warming. The scaling analysis indicates this is mostly due to an increase in the subtropical static stability, which pushes poleward the baroclinically unstable zone and hence the poleward edge of the Hadley cell. The relation between the trends in the Hadley cell edge and the ITCZ is also discussed.
\end{abstract}

\section{Introduction}

The Hadley cell (HC), one of the most prominent circulation features of the earth's atmosphere, plays a pivotal role in shaping the tropical-to-subtropical climate. Its descending branch determines the location of the large-scale subtropical dry zone and its ascending branch determines the location of the intertropical convergence zone (ITCZ). The HC undergoes a continuous seasonal migration and is subject to the influence of the internal climate variability from interannual (Hou 1993, 1998; Chang 1995) to multidecadal time scales (Mantsis and Clement 2009). In particular, the meridional extent of the $\mathrm{HC}$ is found to be responsive to climate change forcings such as greenhouse gas increase (Lu et al. 2007; Frierson et al. 2007) and stratospheric ozone depletion (Son et al. 2010; Kang et al. 2011).

Corresponding author address: Sarah M. Kang, School of Urban and Environmental Engineering, Ulsan National Institute of Science and Technology, 100 Banyeon-ri, Eonyang-eup, Ulsan 689-798, South Korea.

E-mail: skang@unist.ac.kr
$\mathrm{Lu}$ et al. (2007) found that phase 3 of the Coupled Model Intercomparison Project (CMIP3) models unanimously project a widening trend of the $\mathrm{HC}$ in their twenty-first-century climate change scenarios and the subtropical dry zone expands poleward in accordance. They also tested two competing theories for the HC width: the nearly inviscid axisymmetric circulation theory (Schneider 1977; Held and Hou 1980) and the more heuristic view (Held 2000) that interprets the HC edge as being set by the criterion for baroclinic instability. By applying the two scaling theories to the annual-mean data, the $\mathrm{HC}$ expansion under global warming is found to be largely attributable to the increase of the subtropical static stability. Its stabilizing effect on the baroclinic waves at the poleward flank of the $\mathrm{HC}$ acts to extend the breakdown of the thermally direct angular momentum regime to a higher latitude.

However, since the annual-mean state is not physically realized in the real atmosphere, it is questionable if the interpretation for the annual-mean change can be extended to each season given the nonlinear dynamics of the HC (Held and Hou 1980; Lindzen and Hou 1988; Plumb and Hou 1992; Fang and Tung 1999). For instance, 
the winter $\mathrm{HC}$ is relatively closer to the nearly inviscid limit while the summer $\mathrm{HC}$ is more subject to the influence of eddy momentum fluxes originating from the midlatitudes (Schneider and Bordoni 2008; Bordoni and Schneider 2010). To distinguish the contrasting dynamical regimes between the winter and summer cells, Walker and Schneider (2006) introduced a local Rossby number (Ro),

$$
\begin{aligned}
\text { Ro } & \equiv-\zeta / f \quad \text { where } \quad \zeta=-\frac{1}{a \cos \phi}\left(\frac{\partial}{\partial \phi} u \cos \phi\right) \text { and } \\
f & =2 \Omega \sin \phi
\end{aligned}
$$

where $\zeta$ is zonal-mean relative vorticity, $f$ is planetary vorticity, $u$ is the zonal-mean zonal wind, and $\Omega$ is the earth's angular velocity. The Ro is a nondimensional measure of the proximity of the tropical circulation to the inviscid angular momentum conserving (AMC) limit (Adam and Harnik 2013). It also measures the relative importance of the thermal driving versus the eddy driving for the mean meridional circulation. Hence, in the upper branches of the HC, Ro is large in the winter hemisphere and small in the summer hemisphere. We hereby develop and apply to each season a scaling theory that takes into consideration the different dynamical regimes undergone by the $\mathrm{HC}$ throughout the seasonal cycle by introducing the local Rossby number to the Held (2000) scaling.

We show that the application of the modified scaling to the cross-equatorial winter cell corroborates the interpretation of the Held (2000) for the annual-mean HC expansion under global warming, whereas it appears less adequate for the summer cell. Moreover, this exercise reveals an intriguing link between the locations of the ITCZ and the HC edge.

\section{Scaling theory}

Following Held (2000), the HC edge can be viewed as the poleward limit of the AMC until the resulting vertical shear becomes baroclinically unstable. The scaling for the $\mathrm{HC}$ edge is thus obtained by finding the solution for the latitude at which the angular momentum conserving zonal wind equals the baroclinically critical zonal wind. However, the angular momentum is not perfectly conserved especially in the summer HC. Hence, here we generalize the scaling to all seasons by dropping the constraint of AMC for the upper-level wind profile except between the ITCZ and the equator (Fig. 1). Instead, a constant Rossby number, Ro in Eq. (1), is introduced that measures the extent to which the wind deviates from the AMC state between the ITCZ and the HC

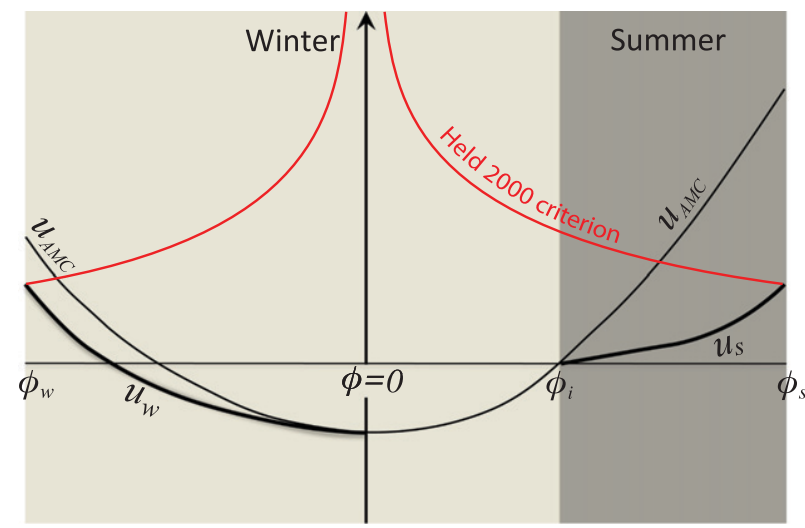

FIG. 1. Schematic for a scaling relation that distinguishes the winter from the summer HC. The thin solid line represents the angular momentum conserving zonal wind profile $\left(u_{\mathrm{AMC}}\right)$, obtained under the assumption of $u=0$ at the ITCZ $\phi_{i}$. The red lines represent the Held (2000) criterion for baroclinic instability. Their intersections with the actual zonal wind profiles (thick lines) determine the edges of the Hadley cell. The zonal wind in summer $\left(u_{s}\right)$ deviates more from $u_{\mathrm{AMC}}$ compared to the zonal wind in winter $\left(u_{w}\right)$, indicative of smaller Ro in summer, so that the $\mathrm{HC}$ edge in summer $\left(\phi_{s}\right)$ reaches higher latitudes than that in winter $\left(\phi_{w}\right)$.

edge. The value for Ro is less than or equal to 1, with Ro $=1$ corresponding to the perfect AMC state.

Let us start with the cross-equatorial winter $\mathrm{HC}$ by integrating Eq. (1) from the equator to the winter $\mathrm{HC}$ edge $\phi_{w}$,

$$
u_{w} \cos \phi_{w}-u_{0}=\frac{\Omega a \mathrm{Ro}}{2}\left(1-\cos 2 \phi_{w}\right),
$$

where $a$ denotes the radius of the earth; $u_{w}$ is the zonalmean zonal wind $(u)$ at $\phi=\phi_{w}$; and $u_{0}$ is $u$ at the equator, obtained by assuming $\mathrm{Ro}=1$ (i.e., AMC) between the equator and the $\operatorname{ITCZ}\left(\phi_{i}\right)$, where $u$ is assumed to be at rest relative to the surface. This is a reasonable assumption since convective clouds in the ITCZ can effectively exchange momentum between the surface and the cloud top level. We then have $u_{0} \approx$ $-\Omega a \phi_{i}^{2}$, using small angel approximation, and substituting it into Eq. (2) gives

$$
u_{w} \approx \Omega a \operatorname{Ro} \phi_{w}^{2}-\Omega a \phi_{i}^{2} .
$$

Now, for the summer HC, we integrate Eq. (1) from the ITCZ to the summer HC edge $\phi_{s}$,

$$
u_{s} \cos \phi_{s}=-\frac{\Omega a \mathrm{Ro}}{2}\left(\cos 2 \phi_{s}-\cos 2 \phi_{i}\right) .
$$

In the small angle approximation, Eq. (4) becomes

$$
u_{s} \approx \Omega a \operatorname{Ro}\left(\phi_{s}^{2}-\phi_{i}^{2}\right) .
$$


On the other hand, the baroclinically unstable zonal wind velocity in the upper troposphere $u_{1}$ can be further determined from the two-layer model's criterion for instability and thermal wind balance,

$$
u_{1}=\frac{g *}{f} \frac{\partial H}{\partial y}=\beta \frac{g * H_{t}}{f^{2}} \approx \frac{g * H_{t}}{2 \Omega a \phi^{2}},
$$

where $g^{*}=g \Delta_{v}$ is the reduced gravity, with $\Delta_{v}$ being the fractional change in potential temperature in the vertical, indicative of the tropospheric gross static stability. Here, $H_{t}$ is the mean thickness of the two-layer model, which is taken as the tropopause height. The HC edge can be obtained as the latitude at which the wind profiles Eq. (3) or (5), depending on the season, coincides with Eq. (6). Equation (3) is used when the ITCZ is located in the opposite hemisphere to the $\mathrm{HC}$ of interest, and Eq. (5) is used when the ITCZ is located in the same hemisphere as the HC. Note here that the location of the ITCZ is set to be the latitude of the zero crossing of the mass streamfunction at $500 \mathrm{hPa}$ between the winter and summer cells, so that the ITCZ location is uniquely defined even though a double ITCZ occurs in precipitation.

To obtain the winter $\mathrm{HC}$ edge, we equate the righthand side of Eq. (3) with the right-hand side of Eq. (6) and find the solution for $\phi_{w}^{2}$,

$$
\phi_{w}^{2}=\frac{\phi_{i}^{2}}{2 \mathrm{Ro}}+\frac{1}{2 \mathrm{Ro}}\left[\phi_{i}^{4}+2 \operatorname{Ro}\left(\frac{g * H_{t}}{\Omega^{2} a^{2}}\right)\right]^{1 / 2} .
$$

For the summer HC edge, we solve the equation $u_{s}=u_{1}$ or Eq. (5) = Eq. (6),

$$
\phi_{s}^{2}=\frac{\phi_{i}^{2}}{2}+\frac{1}{2}\left[\phi_{i}^{4}+\left(\frac{2 g * H_{t}}{\Omega^{2} a^{2} \mathrm{Ro}}\right)\right]^{1 / 2} .
$$

If $\phi_{i}=0$ and Ro $=1$, then we retain the original Held (2000) scaling: $\phi \propto\left(\Delta_{v} H / \Omega^{2} a^{2}\right)^{1 / 4} \propto(N H / \Omega a)^{1 / 2}$, where $N$ is the vertically averaged Brunt-Väisälä frequency, as in Lu et al. (2007).

\section{Data and methods}

The model data for four scenarios (1pctto2x: 20 models; 1pctto4x: 12 models; A1B: 22 models; and A2: 15 models) from the Fourth Assessment Report (AR4) of the Intergovernmental Panel on Climate Change (IPCC) are used for the scaling analysis. Only the first ensemble member of each model is considered. To identify the climate change response, we compute the linear trend for the 100-yr period starting from the year 2001.
The HC edge, denoted as $\phi_{\Psi 500}$, is defined by the latitude of the first zero crossing - going poleward from the extremum - of the zonal-mean mass streamfunction $\Psi$ at $500 \mathrm{hPa}$, computed by vertically integrating the zonal-mean density-weighted meridional wind component from the model top downward. The simulated HC edge $\phi_{\Psi 500}$ is compared with the scaled HC edge from Eq. (7) or (8) depending on the season.

We now describe how the variables in the scaling are computed. The tropopause height $H_{t}$ is computed from temperature data as the lowest pressure level at which the lapse rate decreases to $2^{\circ} \mathrm{C} \mathrm{km}^{-1}$, following the algorithm of Reichler et al. (2003). The static stability $\Delta_{v}$ is computed as $\left[\theta\left(H_{t}\right)-\theta(1000 \mathrm{hPa})\right] /\left(2 \theta_{m}\right)$, where $\theta_{m}$ is the mean tropospheric potential temperature, set to be $290 \mathrm{~K}$, typical of the surface temperature near the subtropics. For the scaling, $\Delta_{v} H_{t}$ averaged between $20^{\circ} \mathrm{S} / \mathrm{N}$ and $40^{\circ} \mathrm{S} / \mathrm{N}$ is used. The local Rossby number Ro is chosen a posteriori to best match the scaled $\phi_{\Psi 500}$ with the simulated $\phi_{\Psi 500}$ for the SH ensemble-mean climatology in each season. As a result, the SH Ro varies with season: for December-February (DJF), March-May (MAM), June-August (JJA), and September-November $(\mathrm{SON})$, the southern Ro $=0.45,0.50,0.98$, and 0.70 . Then, the NH Ro is determined empirically based on its relative magnitude with respect to the $\mathrm{SH}$ values in the observations: for DJF, MAM, JJA, and SON, the northern Ro $=1.00,0.95,0.50$, and 0.50. Hence, Ro varies with both season and hemisphere, but once decided it is kept unchanged with year, scenario, and model. When the ITCZ is in the opposite hemisphere to the HC (DJF and MAM in the NH and JJA and SON in the $\mathrm{SH})$, there is a strong cross-equatorial $\mathrm{HC}$ with Ro $\rightarrow 1$. In contrast, when the ITCZ is in the same hemisphere as the HC (in the other two seasons), Ro is relatively small indicating the strong influence of eddy momentum fluxes.

\section{Results}

We first examine the scaling for the climatologicalmean $\mathrm{HC}$ edge. Figure 2 compares the first 20 -yr mean of the simulated $\phi_{\Psi 500}$ in the abscissa against the scaled $\phi_{\Psi 500}$ in the ordinate for each season in both hemispheres. Since, by design, Ro in the $\mathrm{SH}$ is chosen for each season to match the scaled $\phi_{\Psi 500}$ with the simulated $\phi_{\Psi 500}$ in terms of ensemble mean, the agreement of the ensemble mean between the scaled and the simulated $\phi_{\Psi 500}$ is perfect in the SH (Fig. 2a). However, there is little evidence that the scaling captures the intermodel difference in the climatology. This is not our intention either since many factors other than those considered in the scaling can cause the intermodel spread. On the 
(a) $\mathrm{SH}$

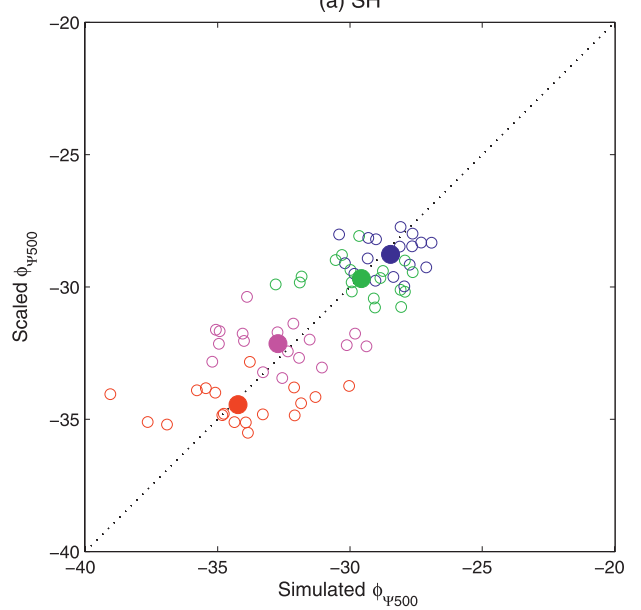

(b) $\mathrm{NH}$

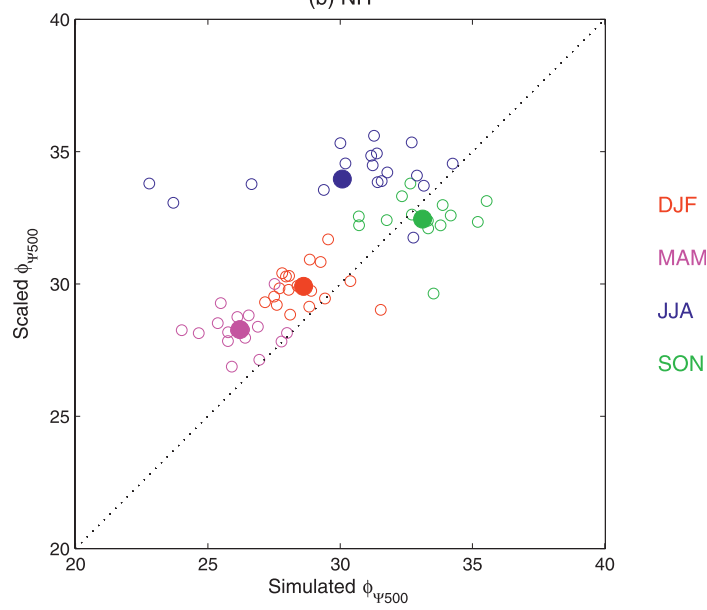

FIG. 2. The first 20-yr mean of the HC edge vs its scaling for the (a) SH and (b) NH from 1pctto2x scenario for each season (DJF in red; MAM in pink; JJA in blue; SON in green). Each circle corresponds to different models, and the multimodel ensemble-mean response is denoted by large filled circles.

other hand, the degree of agreement for the ensemble mean in the $\mathrm{NH}$ can be thought of as an independent validation of the scaling. The seasonality in the ensemblemean $\mathrm{HC}$ edge in the $\mathrm{NH}$ is reasonably captured by the scaling with the NH summer cell being an outlier. For the NH cell in JJA, the scaled $\phi_{\Psi 500}$ is about $4^{\circ}$ poleward of the simulated $\phi_{\Psi 500}$. Although the scaling relationship is not expected to work well in the $\mathrm{NH}$ during summer because the $\mathrm{HC}$ is very weak that the edge is sometimes ill defined and that the cell is greatly affected by extratropical processes and zonal asymmetry, part of the overestimation of the scaling may be blamed on the severe equatorward bias in some models that put their $\mathrm{NH} \mathrm{HC}$ edge during summer too equatorward compared to the observed value of $35^{\circ} \mathrm{N}$.
The $\phi_{\Psi 500}$ seasonality can be mostly attributed to the seasonality in the value of Ro prescribed in the scaling, which is larger in winter and smaller in summer, since the scaled $\phi_{\Psi 500}$ is inversely proportional to Ro following Eqs. (7) and (8). A smaller Ro implies larger deviation from the angular momentum conserving wind $u_{\mathrm{AMC}}$ (Fig. 1), so that the summer/fall HC with weaker subtropical wind can reach farther poleward until it becomes baroclinically unstable. Hence, as shown in Fig. 3, in summer and fall of each hemisphere, the $\mathrm{HC}$ edge reaches farther poleward than during the other two seasons. In addition, for a given Ro, the absolute magnitude of the ITCZ latitude can contribute to the seasonality in the mean $\mathrm{HC}$ extent. As implied in our scaling relation, Eqs. (7) and (8), for a fixed Ro, the HC (a) $\mathrm{SH}$

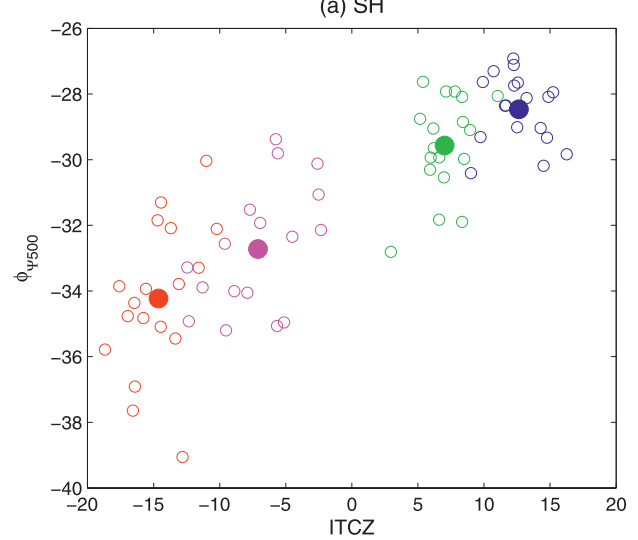

(b) $\mathrm{NH}$

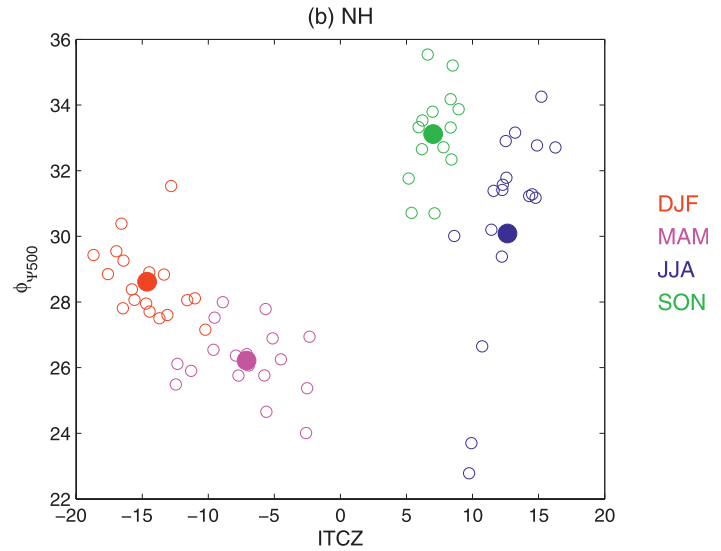

FIG. 3. The first 20-yr mean of the ITCZ vs the HC edge for the (a) SH and (b) NH from 1pctto2x scenario for each season (DJF in red; MAM in pink; JJA in blue; SON in green). Each circle corresponds to different models, and the multimodel ensemble-mean response is denoted by large filled circles. 
extent increases with the absolute magnitude of the ITCZ latitude. This is due to the fact that, as the ITCZ approaches the equator, $u_{\mathrm{AMC}}$ becomes baroclinically unstable faster (Fig. 1), resulting in a more equatorward $\mathrm{HC}$ edge. For example, despite similar magnitude of the prescribed Ro in DJF and MAM in both hemispheres, as the ITCZ is farther away from the equator in DJF, $\phi_{\Psi 500}$ in DJF is at the poleward side of the $\phi_{\Psi 500}$ in MAM. This relationship seems to partly explain the intermodel spread within one season as well: the models with a more poleward ITCZ tend to locate the HC edge more poleward.

We next move on to the seasonality in the trend of the HC edge. As shown in Fig. 4, in terms of ensemble mean, the $\mathrm{HC}$ edge extends poleward in all scenarios and seasons, which is diagnosable by our scaling. An exception is the scenario 1pctto2x over the $\mathrm{NH}$ and during summer, which is likely caused by the outlier models that have severe equatorward bias in the climatologicalmean northern cell during summer (Fig. 2b). Considering that our scaling ignores the extratropical sources of change that are shown by a number of recent studies to affect the $\mathrm{HC}$ edge trend such as the rise of tropopause (Lorenz and DeWeaver 2007), increase of midlatitude eddy phase speed (Chen et al. 2008; Lu et al. 2008), upper-level midlatitude baroclinicity (Riviẽre 2011), and the increase of the spatial scale of the midlatitude eddies (Kidston et al. 2011), the scaling works reasonably well in capturing the ensemble-mean trend of the HC edge, particularly in the SH. Thus, we proceed to examine what factors are responsible for the $\phi_{\Psi 500}$ trend based on the scaling relation with the focus on the $\mathrm{SH}$.

Figure 5 compares the simulated $\phi_{\Psi 500}$ trend with its scaling for each model and scenario in austral winter and summer. In each panel, the significance of the correlation between the scaling factor and the simulated trend is displayed in brackets. Given the degrees of freedom of 59, the correlations are all significant at 5\% according to the two-tailed Student's $t$ test. Because the summer cell is more susceptible to the influence of the midlatitude eddies, the change of which is often extratropically originated and independent of the tropical heating, the scaling is expected to work better in winter. Indeed, the scaling performs better for JJA than DJF in accounting for the intermodel spread of the simulated $\phi_{\Psi 500}$ trend, with a higher correlation coefficient in JJA (0.53) than in DJF (0.37). As the scaling works modestly in both seasons, we partition the trend into changes in $\Delta_{v}$ and $H_{t}$, and changes in ITCZ location. It is clear that the multimodel ensemble-mean expansion is predominantly caused by the changes in subtropical-to-midlatitude static stability and the associated tropopause rise; with these two factors

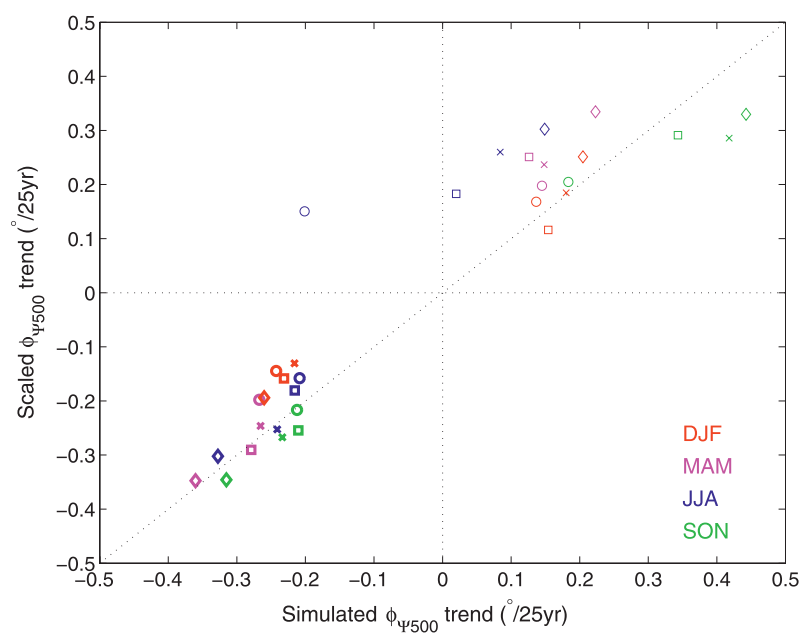

FIG. 4. The ensemble-mean trend of the $\mathrm{HC}$ edge vs its scaling for the $\mathrm{SH}$ in thick markers and for the $\mathrm{NH}$ in thin markers for each season (DJF in red; MAM in pink; JJA in blue; SON in green): 1pctto $2 \mathrm{x}$ in circle, 1 pctto $4 \mathrm{x}$ in square, $\mathrm{A} 1 \mathrm{~B}$ in cross, and $\mathrm{A} 2$ in diamond.

fixed in the scaling (middle panel), the mean expansion vanishes. The shift of the ITCZ also makes discernible contribution to the intermodel spread. The effect of the ITCZ trend on the $\phi_{\Psi 500}$ trend is further illustrated in Fig. 6. The $\phi_{\Psi 500}$ trend in summer is positively correlated with the ITCZ shift and vice versa in winter. In austral winter (summer), the ITCZ is in the NH (SH), so that the positive ITCZ trend indicates a poleward (equatorward) shift. Hence, Fig. 6 indicates that $\phi_{\Psi 500}$ in both seasons shifts more poleward as the ITCZ shifts more poleward with climate change, a behavior consistent with the scaling relations Eqs. (7) and (8). The opposite direction of movement between the winter $\mathrm{HC}$ edge and the ITCZ can be interpreted as the consequence of the enhancement of the winter cell wind and its inclination toward instability as the ITCZ in the summer hemisphere moves equatorward (cf. Fig. 1).

\section{Summary and discussion}

We expand the scaling theory of Held (2000) for the $\mathrm{HC}$ edge to distinguish the contrasting dynamical regimes between the winter and summer cells by introducing local Rossby number, Ro, following Walker and Schneider (2006). The HC edge is then determined as the poleward extent at which the sub-AMC zonal wind profile constrained by Ro first becomes baroclinically unstable. As a follow-up to the study of Lu et al. (2007), we examine the seasonality of the scaling relationships by relaxing the assumption of AMC.

By fitting the scaling formula toward the ensemblemean $\mathrm{HC}$ edge simulated by the CMIP3 models, we 

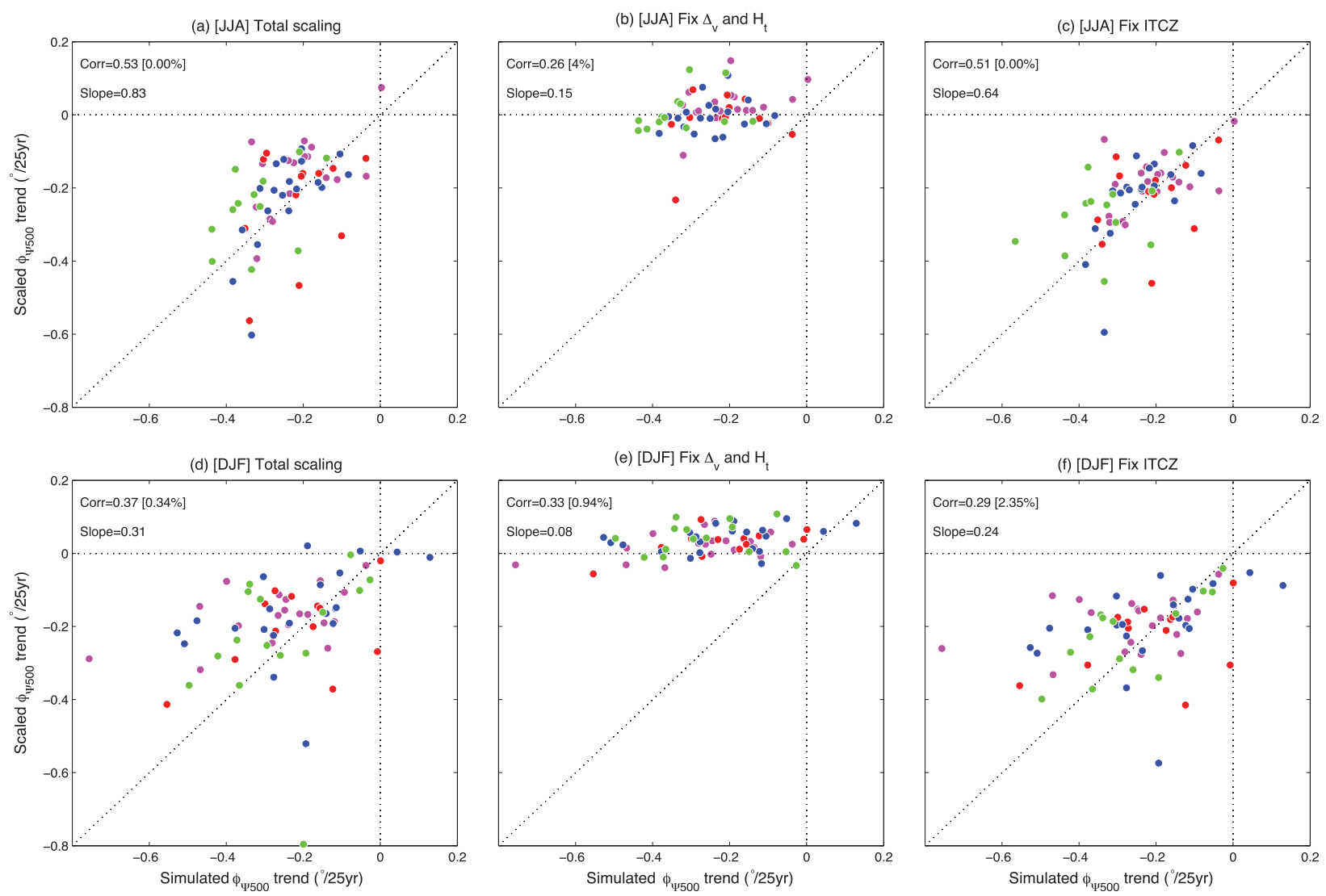

FIG. 5. The HC edge trend vs its scaling for the SH in (top) JJA and (bottom) DJF. The ordinates denote (left) the total scaling, (middle) the scaling with $\Delta_{v}$ and $H_{t}$ fixed to their first 20-yr mean, and (right) the scaling with the ITCZ latitude fixed to its first 20-yr mean. Each circle corresponds to different models: 1 pctto2x in pink, 1 pctto4x in red, A1B in blue, and A2 in green. The correlation coefficient and slope between the simulated and scaled HC edge are given in the top-left corner of each panel. The corresponding significant level of the correlation is displayed in brackets.

begin to explain the seasonality in the climatological HC: that is, that the summer cell extends more poleward than the winter cell. This is primarily dictated by the seasonality in the prescribed Ro, whose value is small in summer (indicative of greater influence of extratropical eddies) and large in winter (indicative of proximity to the AMC state). With smaller (larger) Ro, the zonal wind deviates more (less) from the AMC wind profile so as to be able to extend farther (less) poleward before it becomes baroclinically unstable. Also, when Ro is similar, the $\mathrm{HC}$ edge extends more poleward in solstices than equinoxes because the ITCZ in the former is located farther away from the equator, the associated thermally forced wind is weaker, and the breakdown of the thermally driven cell is delayed to higher latitudes.

Furthermore, over the SH during both winter and summer, a robust poleward expansion of the $\mathrm{HC}$ in several scenarios of the twenty-first century with varying extent of $\mathrm{CO}_{2}$ concentration increase is successfully diagnosed by our scaling relation. It suggests that the $\mathrm{HC}$ expansion in both seasons largely results from the increase in gross static stability and the tropopause rise near the subtropics, as in Lu et al. (2007), where only annual means have been analyzed. Also, the HC edge trend is shown to be related with the ITCZ trend in the intermodel spread: the trend in $\mathrm{HC}$ expansion is larger as the ITCZ shifts farther away from the equator.

Finally, caution should be used to avoid literal interpretation of the result of the scaling. The scaling here is built on the conception of the $\mathrm{HC}$ being thermally forced, whereas we are fully aware of that the outer portion of the $\mathrm{HC}$ is mainly maintained by the eddy momentum divergence (Kim and Lee 2001). The demonstrated skill of the scaling is only intended for highlighting the most essential dynamical factors in the tropics and subtropics that can contribute to the robust $\mathrm{HC}$ expansion under global warming. Extratropical processes not included in the scaling could play as important roles in changing the structure of the $\mathrm{HC}$, as demonstrated by previous studies (i.e., Lu et al. 2008; Kang et al. 2011). Additionally, in view of that the ITCZ response to $\mathrm{CO}_{2}$ forcing can originate from the extratropics 


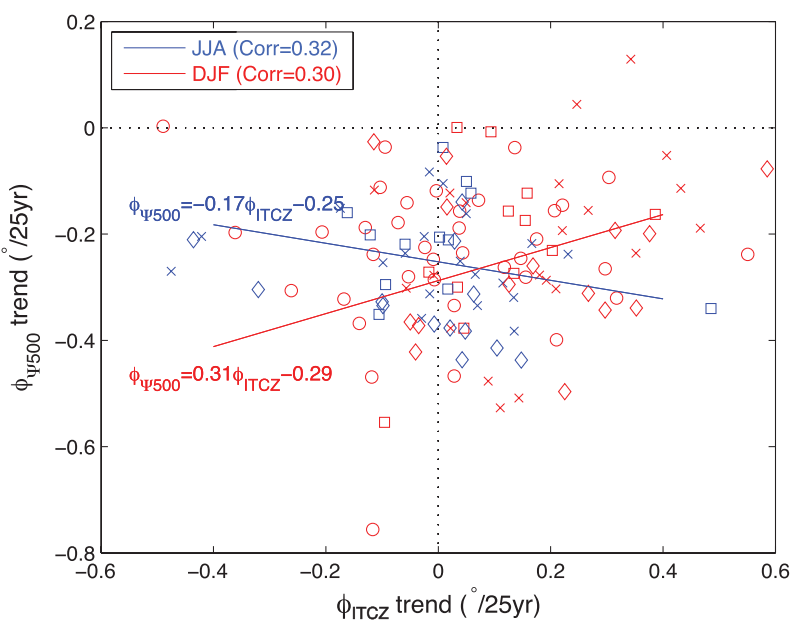

FIG. 6. The trend of the $\mathrm{HC}$ edge vs the trend of the ITCZ for the $\mathrm{SH}$ in JJA (blue) and DJF (red): 1pctto2x in circle, 1pctto4x in square, $\mathrm{A} 1 \mathrm{~B}$ in cross, and $\mathrm{A} 2$ in diamond. Positive value corresponds to northward movement. The correlation coefficient for each season is also displayed, both being significant at above 5\% level.

(Frierson and Hwang 2012), the extratropical dynamics has to be considered to achieve a fuller understanding of the HC expansion under global warming.

Acknowledgments. We thank Thomas Reichler and an anonymous reviewer for their constructive comments and suggestions. Discussion with Ori Adam on the limitation of the angular momentum conservation in the Hadley cell is also appreciated. We acknowledge the international modeling groups for providing their datasets for analysis and the Program for Climate Model Diagnosis and Intercomparison (PCMDI) for collecting and archiving the model data. The IPCC Data Archive at Lawrence Livermore National Laboratory is supported by the Office of Science, U.S. Department of Energy. S. M. Kang is supported by the year 2011 Research Fund of the Ulsan National Institute of Science and Technology (UNIST), and J. Lu is partially supported by NSF Grant AGS-1064045.

\section{REFERENCES}

Adam, O., and N. Harnik, 2013: Idealized annually averaged macroturbulent Hadley circulation in a shallow water model. J. Atmos. Sci., in press

Bordoni, S., and T. Schneider, 2010: Regime transitions of steady and time-dependent Hadley circulations: Comparison of axisymmetric and eddy-permitting simulations. J. Atmos. Sci., 67, 1643-1654.

Chang, E. K. M., 1995: The influence of Hadley circulation intensity changes on extratropical climate in an idealized model. J. Atmos. Sci., 52, 2006-2024.

Chen, G., J. Lu, and D. M. W. Frierson, 2008: Phase speed spectra and the latitude of surface westerlies: Interannual variability and global warming trend. J. Climate, 21, 5942-5959.

Fang, M., and K. K. Tung, 1999: Time-dependent nonlinear Hadley circulation. J. Atmos. Sci., 56, 1797-1807.
Frierson, D. M. W., and Y.-T. Hwang, 2012: Extratropical influence on ITCZ shifts in slab ocean simulations of global warming. J. Climate, 25, 720-733.

_ J. Lu, and G. Chen, 2007: Width of the Hadley cell in simple and comprehensive general circulation models. Geophys. Res. Lett., 34, L18804, doi:10.1029/2007GL031115.

Held, I. M., 2000: The general circulation of the atmosphere. Proc. Geophysical Fluid Dynamics Program, Woods Hole, MA, Woods Hole Oceanographic Institute, 1-70. [Available online at http://gfdl.noaa.gov/cms-filesystem-action/user_files/ih/lectures/ woods_hole.pdf.]

— , and A. Y. Hou, 1980: Nonlinear axially symmetric circulations in a nearly inviscid atmosphere. J. Atmos. Sci., 37, 515-533.

Hou, A. Y., 1993: The influence of tropical heating displacements on the extratropical climate. J. Atmos. Sci., 50, 3553-3570.

_ 1998: Hadley circulation as a modulator of the extratropical climate. J. Atmos. Sci., 55, 2437-2457.

Kang, S. M., L. M. Polvani, J. C. Fyfe, and M. Sigmond, 2011: Impact of polar ozone depletion on subtropical precipitation. Science, 332, 951-954.

Kidston, J., G. K. Vallis, S. M. Dean, and J. A. Renwick, 2011: Can the increase in the eddy length scale under global warming cause the poleward shift of the jet streams? J. Climate, 24, 3764-3780.

Kim, H.-K., and S. Lee, 2001: Hadley cell dynamics in a primitive equation model. Part II: Nonaxisymmetric flow. J. Atmos. Sci., 58, 2859-2871.

Lindzen, R. S., and A. V. Hou, 1988: Hadley circulations for zonally averaged heating centered off the equator. J. Atmos. Sci., 45, 2416-2427.

Lorenz, D. J. and E. T. DeWeaver, 2007: Tropopause height and zonal wind response to global warming in the IPCC scenario integrations. J. Geophys. Res., 112, D10119, doi:10.1029/ 2006JD008087.

Lu, J., G. A. Vecchi, and T. Reichler, 2007: Expansion of the Hadley cell under global warming. Geophys. Res. Lett., 34, L06805, doi:10.1029/2006GL028443.

, G. Chen, and D. M. W. Frierson, 2008: Response of the zonal mean atmospheric circulation to El Niño versus global warming. J. Climate, 21, 5835-5851.

Mantsis, D. F. and A. C. Clement, 2009: Simulated variability in the mean atmospheric meridional circulation over the 20th century. Geophys. Res. Lett., 36, L06704, doi:10.1029/2008GL036741.

Plumb, R. A., and A. Y. Hou, 1992: The response of a zonally symmetric atmosphere to subtropical thermal forcing: Threshold behavior. J. Atmos. Sci., 49, 1790-1799.

Reichler, T., M. Dameris, and R. Sausen, 2003: Determining the tropopause height from gridded data. Geophys. Res. Lett., 30, 2042, doi:10.1029/2003GL018240.

Riviẽre, G., 2011: A dynamical interpretation of the poleward shift of the jet streams in global warming scenarios. J. Atmos. Sci., 68, 1253-1272.

Schneider, E. K., 1977: Axially symmetric steady-state models of the basic state for instability and climate studies. Part II. Nonlinear calculations. J. Atmos. Sci., 34, 280-296.

Schneider, T., and S. Bordoni, 2008: Eddy-mediated regime transitions in the seasonal cycle of a Hadley circulation and implications for monsoon dynamics. J. Atmos. Sci., 65, 915-934.

Son, S.-W., and Coauthors, 2010: Impact of stratospheric ozone on Southern Hemisphere circulation change: A multimodel assessment. J. Geophys. Res., 115, D00M07, doi:10.1029/2010JD014271.

Walker, C. C., and T. Schneider, 2006: Eddy influences on Hadley circulations: Simulations with an idealized GCM. J. Atmos. Sci., 63, 3333-3350. 